\title{
Clayey Sand Soil's Behaviour Analysis and Imaging Subsurface Structure via Engineering Characterizations and Integrated Geophysicals Tomography Modeling Methods
}

\author{
Andy Anderson Bery, Rosli Saad \\ Geophysics Section, School of Physics, Universiti Sains Malaysia, Penang, Malaysia \\ Email: andersonbery@yahoo.com.my
}

Received November 5, 2011; revised December 20, 2011; accepted January 21, 2012

\begin{abstract}
The geoelectrical resistivity and seismic refraction surveys which were used in this study on the test site, delivered a detailed image of the near-surface conditions in generally very good. Electrical resistivity and seismic refraction analysis proved that a combination of these integrated study of the physical environmental data provided a reasonable compromise between measurement time and image resolution. Quantitative interpretation of the resistivity and seismic models based on soil's parameters determined using laboratory practices and field survey could reproduce the range of resistivity and seismic values found on the site very well. The model explains the ambiguity in between resistivity and clayey sands found on the site and predict the dominant role of water saturation. Geophysical methods are used in this research in purpose to determine the internal structure of a soil mass. Various geophysical methods and their merits for imaging subsurface structures and condition are discussed. Seismic methods are often the most suitable because the measurements depend on the mechanical properties which are also important in the mechanical calculation of soil's behaviour analysis. Other geophysical method, such as geoelectric resistivity, is useful to determine the internal structure, but require a correlation of found boundaries with mechanical properties. This research was conducted to investigate the subsurface structures and conditions through geotechnical engineering properties and its geophysical characteristics. The computation analysis is used in this research in purpose to investigate clayey sand soil's behaviour. Electrical resistivity test and engineering laboratory practices such as soil strength test, liquid limit test, plastic limit test and grain size distribution test was also carried out to investigate clayey sand soil behaviour in Batu Uban, Penang area during monitoring period.
\end{abstract}

Keywords: Geoelectrical Resistivity; Seismic Refraction; Soil's Behaviour; Investigate; Monitoring Period

\section{Introduction}

Natural disasters that occur suddenly such as landslide can cause death and economic losses such as damaging buildings, roads and vehicles [1,2]. The prediction of any natural disaster before it occurs will reduce or stop these hazards. There are internal factors which can cause soil stability problems such internal subsurface structure and the amount of groundwater, sliding subsurface and water movement that can be imaged by geophysical techniques [3]. The subsurface structure is a crucial factor which affects slope stability [4]. Groundwater, water movement and the sliding subsurface are the most important internal factor of unstable slope stability [5]. Tropical countries which have a high annual rainfall and a high temperature can cause weathering and form thick soil and weathered rock layers. Tropical countries face natural disasters such as landslide due to this climate and causative factors such as geological condition.

The insitu behaviour of soils is complex because it is heavily dependent upon numerous factors. To acquire appropriate understanding, it is necessary to analyze them not only through geophysics and geotechnical engineering skills but also through other associated disciplines like geology, geomorphology, climatology and other earth and atmosphere related sciences [3].

In the last decade for instance, research studies related to the influence of fines on liquefaction potential accelerated markedly [6-8]. The purpose of these investigations was to quantify the effect of fines on the liquefaction potential of soils containing nonplastic fines. The role of fines in liquefaction mechanism is not fully understood yet $[8,9]$. These fines may affect the compression characteristics of coarse grained soils as well. In some mod- 
els proposed for compression behaviour of cohesionless soils such as those by $[10,11]$; effects of initial void ratio, relative density, particle shape, mineralogy, structure and applied stress conditions were mentioned. These factors were also prominent in the experimental researches related to the compression of sands $[12,13]$.

Study in basic engineering properties such as the grain size distributions, hardness, strength, durability and shear strength parameters (cohesion, C' and friction angle, $\varnothing^{\prime}$ ) is important to understand the behaviour for older alluvium and avoid the inherence problems [14]. Many previous researchers [15-19] studied the changes of engineering properties for igneous and sedimentary rocks but very minimal works has been carried out for older alluvium.

\section{Research Objectives}

The first objective of the present study is to systematiccally investigate the behaviour of clayey sand soils from the perspective of cohesion, friction angle, void ratio, porosity and saturation degree concept that are based on experimental evidence obtained during the interaction between fine (clay) and medium grain (sand) matrices. Influence of the grain matrices content and stress conditions on this interaction has been studied by means of SCIP tester and direct shear tests performed on clayey sand soil samples. The second objective of this research is to investigate the slope stability through soil's geotechnical properties and its geophysical characterizations. Prior of that, the research combines the integrated study of the physical environment with monitoring and investtigative techniques that include social and economic aspects of managing the environment.

\section{Geography and Geology of Study Area}

Penang is the second smallest and one of the 13 states of Peninsular Malaysia. It is situated in the northern region and constituted by two geographically different entitiesan island (area: $293 \mathrm{~km}^{2}$ ) called Penang Island and a portion of mainland called Seberang Perai (area $738 \mathrm{~km}^{2}$ ) connected, besides a regular ferry service, through a 13.5 $\mathrm{km}$ long Bridge. The island is located between latitudes $5^{\circ} 8^{\prime} \mathrm{N}$ and $5^{\circ} 35^{\prime} \mathrm{N}$ and longitudes $100^{\circ} 8^{\prime} \mathrm{E}$ and $100^{\circ} 32^{\prime} \mathrm{E}$. The climate is tropical with the average mean daily temperature about $27^{\circ} \mathrm{C}$ and mean daily maximum and minimum temperature ranging between $31.4^{\circ} \mathrm{C}$ and $23.5^{\circ} \mathrm{C}$ respectively. However, the individual extremes are $35.7^{\circ} \mathrm{C}$ and $23.5^{\circ} \mathrm{C}$ respectively. The mean daily humidity varies between $60.9 \%$ and $96.8 \%$. The average annual rainfall is about $267 \mathrm{~cm}$ and can be as high as $325 \mathrm{~cm}$. The two rainy seasons are south-west monsoons from April to October and north-east monsoons from October to February. The terrain consists of coastal plains, hills and mountains.
Batu Uban area is located about $9.70 \mathrm{~km}$ from the city of Georgetown. The coordinate of the study area is located between latitudes $5^{\circ} 21^{\prime} 43.1^{\prime \prime} \mathrm{N}$ and $5^{\circ} 21^{\prime} 43.6^{\prime \prime} \mathrm{N}$ and longitudes $100^{\circ} 18^{\prime} 19.5^{\prime \prime} \mathrm{E}$ and $100^{\circ} 18^{\prime} 20.1^{\prime \prime} \mathrm{E}$. The geology of the area is medium to coarse-grained biotite granite with granitic bedrock.

There are three main geological formations in Penang and their distribution is as given in Map 1.

\section{Geophysics Techniques Data Acquisition}

Electrical Imaging System is now mainly carried out with a multi-electrode resistivity meter system. Such survey use a number (usually 25 to 100) of electrodes lay out in a straight line with a constant spacing. A computer-controlled system is then used to automatically select the active electrodes for each measure (Griffith and Barker, 1993). Throughout the survey conducted in the proposed site, the Wenner-Schlumberger protocol has been used with the ABEM SAS4000 system. The data collected in the survey can be interpreted using an inexpensive microcomputer. Electrode Selector 464 is a single channel relay matrix switch which connects to Terrameter SAS 4000. In additional, two resistivity cables, 41 stainless steel electrodes and 42 jumpers are used with Terrameter SAS4000 each time survey is done. The electrodes spacing used in this study are fixed at 0.5 meter interval and the length covered in this study is 20 meter in purpose to investigate the subsurface structure changes. Terrameter SAS400 and Electrode Selector were placed at the centre and connected with two resistivity cables. The programme is used for this resistivity imaging, which is RES2 DINV software.

Seismic imaging directs an intense sound source into the ground to evaluate subsurface conditions and to possibly detect high concentrations of contamination. Receivers called geophones, analogous to microphones, pick up "echoes" that come back up through the ground and record the intensity and time of the "echo" on computers. Data processing turns these signals into images of the geologic structure. This technology is similar in principle to active electromagnetic survey technology. For this seismic imaging, there are a few equipment is used to obtain the data from the field. The equipments involved in this seismic survey are a battery pack, a roll of trigger cable, two seismic cables, recording equipment (ABEM Terraloc Mark 8), 24 geophones of 14Hertz, a 12 pounds hammer, a striker metal plate and a log book. Terraloc Mark 8 is placed at the centre of seismic line and was connected to two seismic cables. 12 pounds hammer is used in this study in purpose of to safe the cost compare to gun. In this seismic survey, there 15 numbers of shot points with total of 360 traces recorded and 1.0 meter geophone interval was selected and fixed during study period in purpose to obtained detailed and reliable seismic data at 


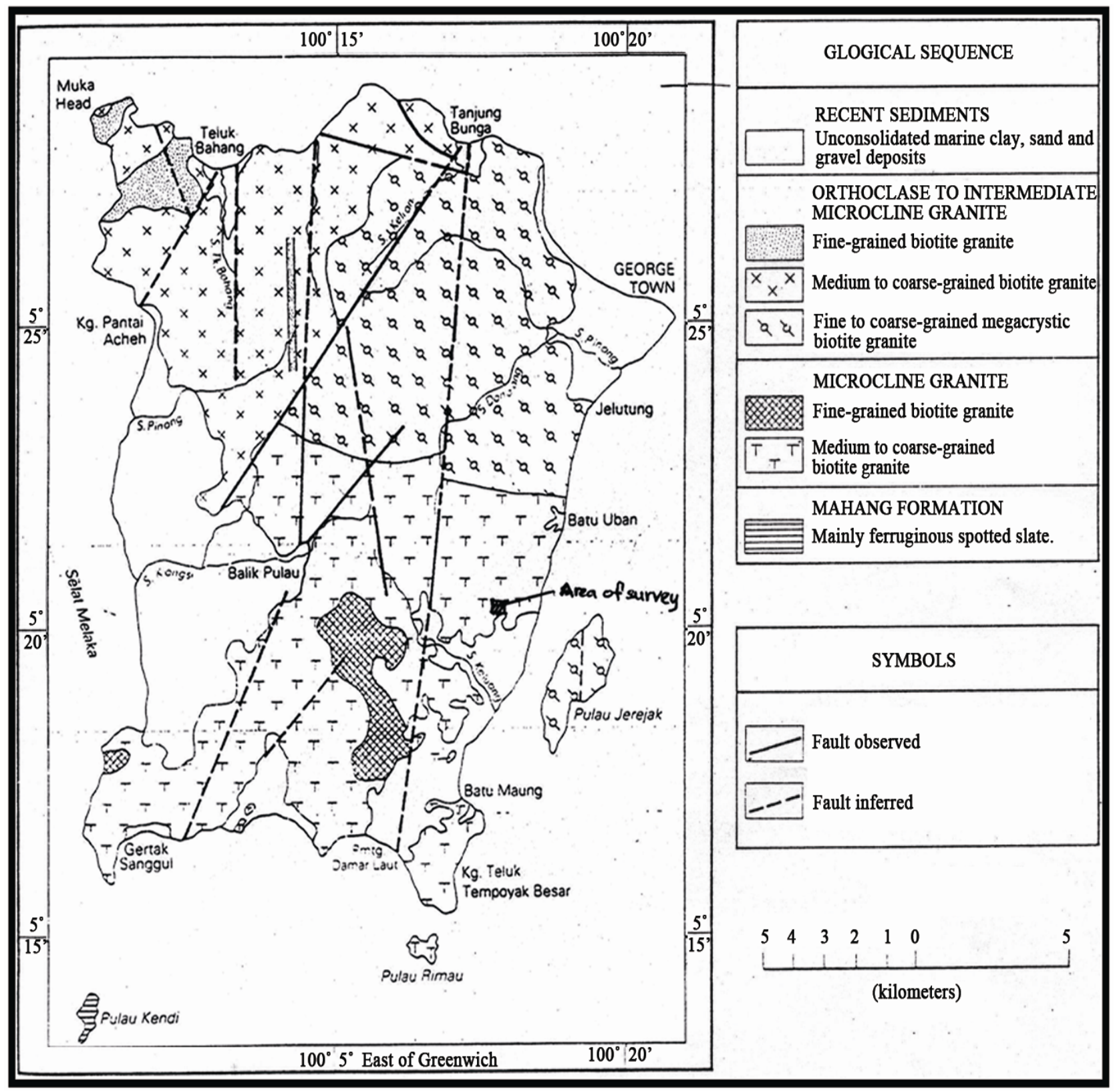

Map 1. Geological map of Penang Island.

shallow depth. Field surveys were conducted at Batu Uban area for 5 times within 5 months that is January 2011 until May 2011. Meanwhile, the resistivity survey also conducted together with seismic survey at Batu Uban area for 5 times within 5 months that is January 2011 until May 2011 along with seismic line. Both geophysics techniques were analyzed together to monitor and investigate the possible subsurface structure changes, water content, bedrock depth, and layer thickness from subsurface image. These two geophysical combination techniques will able to give a better analysis of the subsurface especially water movement and subsurface structure changes.

\section{Soil's Strength and Index Properties}

[20] postulated that the residual strength of mixtures composed of crushed quartz and different clay minerals depend on the relative volumes of clay mineral matrix (e.g. kaolinite, chlorite, illite, and montmorillonite) and massive minerals example is quartz, feldspar, and calcite. It was also stated that when the volume of the massive mineral exceeds about $50 \%$ of the total volume of the mixtures, the residual strength of the mixture is approximately equal to that of the massive mineral. [21] mentioned that residual shear behaviour changes significantly as the clay content of cohesive soil increases and a chan- 
ge in shearing mechanism occurs. [22] also showed that angle of internal friction $\left(\varnothing^{\prime}\right)$ decreases with an increase in clay content for reconstituted soils.

The residual soils are generally found in unsaturated condition. The shear strength of unsaturated soils can be represented by the extended Mohr-Coulomb criterion Equation (1).

$$
\tau_{f f}=\mathrm{c}^{\prime}+\left(\sigma-\mathrm{u}_{\mathrm{a}}\right) \tan \varphi^{\prime}+\left(\mathrm{u}_{\mathrm{a}}-\mathrm{u}_{\mathrm{w}}\right) \tan \varphi^{\mathrm{b}}
$$

$\tau_{f f}=$ shear stress on the failure plane at failure; $\mathrm{c}^{\prime}=$ effective cohesion; $\sigma=$ normal stress; $\mathrm{u}_{\mathrm{a}}=$ pore-air pressure; $\left(\sigma-\mathrm{u}_{\mathrm{a}}\right)=$ net normal stress; $\varphi^{\prime}=$ effective angle of shear resistance; $\mathrm{u}_{\mathrm{w}}=$ pore-water pressure; $\left(\mathrm{u}_{\mathrm{a}}-\mathrm{u}_{\mathrm{w}}\right)=$ matric suction; and $\varphi^{\mathrm{b}}=$ angle indicating the rate of increase in shear strength relative to matric suction. As the soil approaches saturation, the pore pressure, $u_{w}$, approaches the pore pressure, $\mathrm{u}_{\mathrm{a}}$ and Equation (1) becomes:

$$
\tau_{f f}=\mathrm{c}^{\prime}+\left(\sigma-\mathrm{u}_{\mathrm{w}}\right) \tan \varphi
$$

that is the Mohr-Coulomb strength criterion for saturated soils. In applying Equation (2) to unsaturated soils, the shear strength component due to matric suction, that is $\left(\mathrm{u}_{\mathrm{a}}-\mathrm{u}_{\mathrm{w}}\right) \tan \varphi^{\mathrm{b}}$, is masked as the cohesion intercept, $\mathrm{c}=$ $\left(c^{\prime}+\left(u_{a}-u_{w}\right) \tan \varphi^{b}\right)$. Therefore, the cohesion intercept, $c$, in residual soils appear to vary widely [23].

[24] noted the increase of water absorption with weathering grade. [25] found that micro-morphological features in kaolinitic soils were related to compaction, increased tensile strength, penetrometer resistance, bulk density and hard setting behaviour.

\section{Laboratory Practices Results}

Laboratory tests were performed to determine 32 clayey sand soils's engineering characterization during five months period. The percentages of liquid limit, plastic limit and plasticity index of the samples taken from the site are plotted against resistivity and moisture content. Note that, the resistivity of the soil samples increase with the decreasing of the moisture content percentage. Figure 1 shows the correlation of the resistivity and the moisture content of the clayey sandy soil is $\rho=1409.0 \mathrm{e}^{-0.01(\mathrm{~W})}$ and regression coefficient, $\mathrm{R}^{2}$ was approximately 0.504 .

For the empirical correlation between resistivity and internal friction angle, $\phi^{\prime}$ for undisturbed clayey sand soils is $\rho=1378.0 \mathrm{e}^{-0.03\left(\varphi^{\prime}\right)}$ and the regression coefficient, $\mathrm{R}^{2}$ was approximately 0.647 as shown in Figure 2. It shows that internal friction angle is inversely proportional to the resistivity of samples.

In Figure 3, the empirical correlation between resistivity, $\rho$ and undisturbed soil's effective cohesion, $C$ ' for clayey sand soils is found as: $\rho=167.0 \mathrm{e}^{0.101\left(\mathrm{C}^{\prime}\right)}$ and regression coefficient, $\mathrm{R}^{2}$ was approximately 0.664 .

Meanwhile, Figure 4 shows the empirical correlations

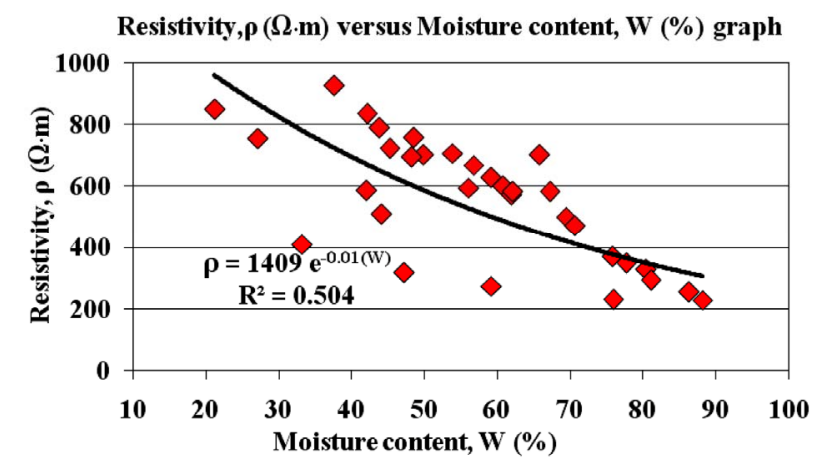

Figure 1. Empirical correlation of resistivity, ( $\rho)$ and moisture content, $(\mathrm{W})$ of 32 clayey sand soil samples.

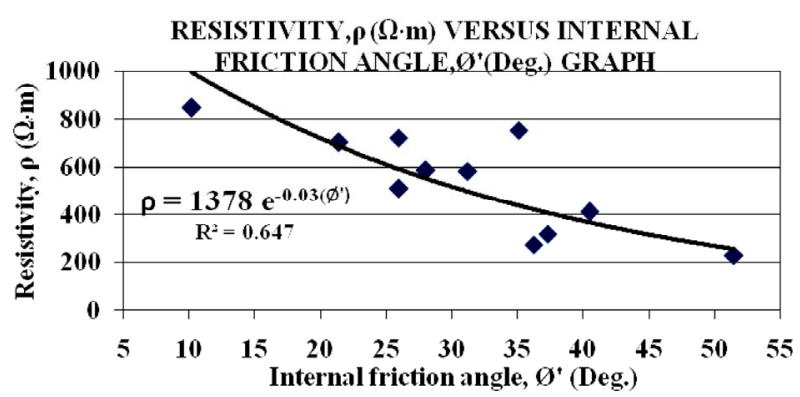

Figure 2. The empirical correlation between resistivity, ( $\rho)$ and internal friction angle, $\phi^{\prime}$ of undisturbed clayey sand soil samples.

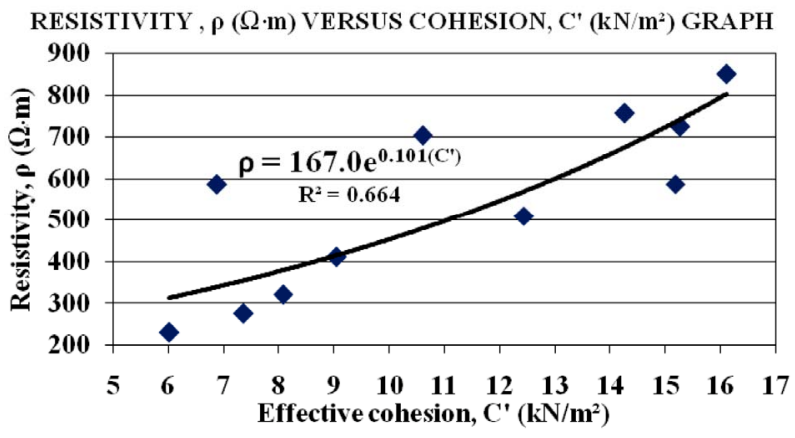

Figure 3. The empirical correlation between resistivity, ( $\rho$ ) and effective cohesion, $C^{\prime}$ of undisturbed clayey sand soil samples.

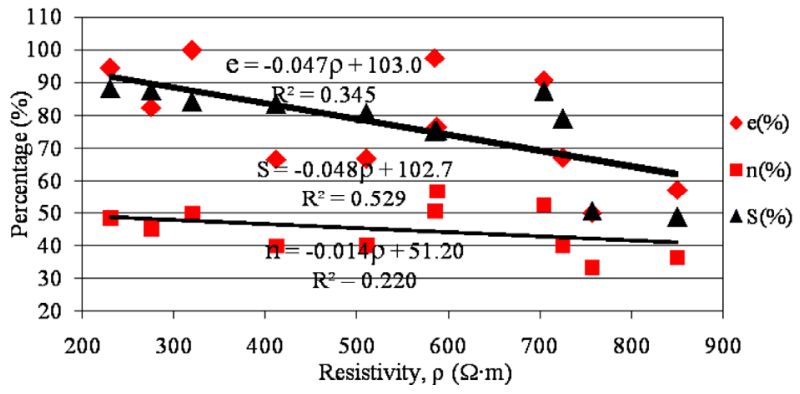

Figure 4. The empirical correlation of void ratio, (e), porosity, (n) and degree of saturation (S) with resistivity, ( $\rho)$ of clayey sand soil samples. 
of void ratio, porosity and degree of saturation with resistivity of clayey sand soil samples. The empirical correlation between resistivity, $\rho$ and void ratio, e is, $\mathrm{e}=-0.047 \rho+103.0$ and its regression coefficient, $\mathrm{R}^{2}$ was approximately 0.345 . The empirical correlation between resistivity with porosity, $\mathrm{n}$ is, $\mathrm{n}=-0.014 \rho+51.20$ and its regression coefficient, $\mathrm{R}^{2}$ was approximately 0.220 . However, the empirical correlation between resistivity, $\rho$ and saturation degree, $\mathrm{S}$ is, $\mathrm{S}=-0.048 \rho+102.7$ and its regression coefficient, $\mathrm{R}^{2}$ was approximately 0.529 .

Figure 5 shows the empirical correlations between moisture content with void ratio, porosity and degree of saturation of clayey sand. The empirical correlation between moisture content, $\mathrm{W}$ and void ratio, e is, $\mathrm{e}=0.845 \mathrm{~W}+36.63$ and its regression coefficient, $\mathrm{R}^{2}$ was approximately 0.692 . The empirical correlation between moisture content, $\mathrm{W}$ with porosity, $\mathrm{n}$ is, $\mathrm{n}=0.317 \mathrm{~W}+28.41$ and its regression coefficient, $\mathrm{R}^{2}$ was approximately 0.724 . However, the empirical correlation between moisture content, $\mathrm{W}$ and saturation degree, $\mathrm{S}$ is, $\mathrm{S}=0.629 \mathrm{~W}+46.30$ and its regression coefficient, $\mathrm{R}^{2}$ was approximately 0.570 .

Figure 6 shows the empirical correlation between liquid limit, $W_{L}$ and resistivity, $\rho$ is found as:

$\mathrm{W}_{\mathrm{L}}=-0.060(\rho)+91.84 \mathrm{~d}$ its regression coefficient, $\mathrm{R}^{2}$ was approximately 0.645 . Then, the empirical correlation between plastic limit, $\mathrm{W}_{\mathrm{p}}$ and resistivity, $\rho$ is found as: $\mathrm{W}_{\mathrm{p}}=-0.018(\rho)+45.89$ nd its regression coefficient, $\mathrm{R}^{2}$ was approximately 0.133 . Meanwhile, the empirical correlation between plasticity index, PI and resistivity, $\rho$ is found as: $\mathrm{PI}=-0.041(\rho)+45.95$ and its regression coefficient, $\mathrm{R}^{2}$ was approximately 0.473 . It shows that all these three parameters are inversely proportional to its resistivity.

Meanwhile, Figure 7 shows the empirical correlation between liquid limit, $\mathrm{W}_{\mathrm{L}}$ and moisture content, $\mathrm{W}$ of 32 clayey sand soil is found as: $\mathrm{W}_{L}=0.829(\mathrm{~W})+10.35$ and its regression coefficient, $\mathrm{R}^{2}$ was approximately 0.876 . The empirical correlation between plastic limit, $\mathrm{W}_{\mathrm{p}}$ and moisture content, $\mathrm{W}$ of clayey sand soil samples is found as: $\mathrm{W}_{\mathrm{p}}=0.258(\mathrm{~W})+20.60$ and its regression coefficient,

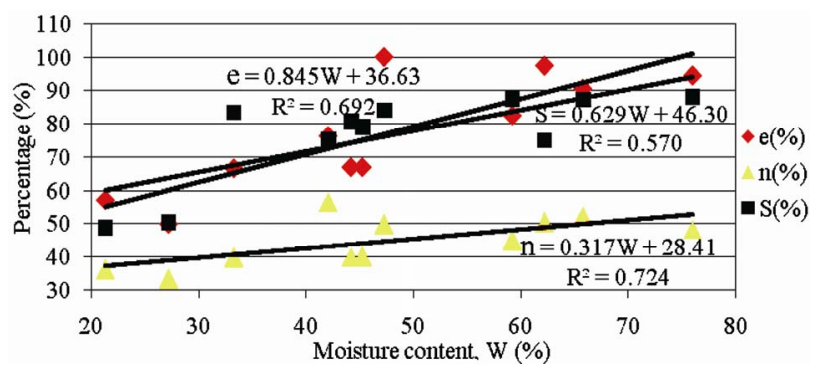

Figure 5. The empirical correlation of moisture content (W) with void ratio, (e), porosity, (n) and saturation degree, (S) of clayey sand soil samples.

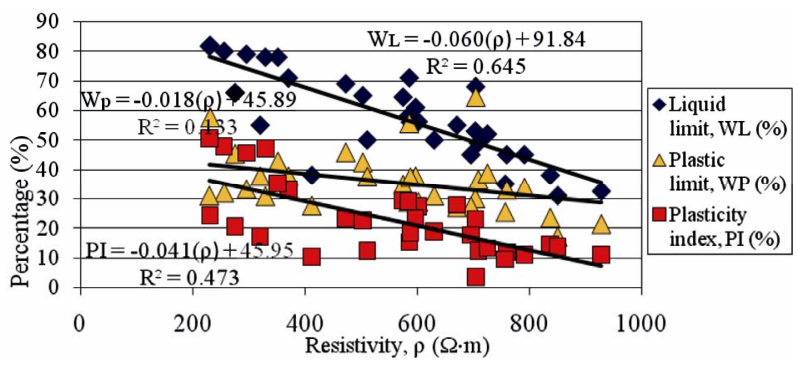

Figure 6. The empirical correlation between liquid limit, $\left(\mathrm{W}_{\mathrm{L}}\right)$, plastic limit, $\left(\mathrm{W}_{\mathrm{p}}\right)$, and plasticity index, $(\mathrm{PI})$ with resistivity, ( $\rho)$ of 32 clayey sand soil samples.

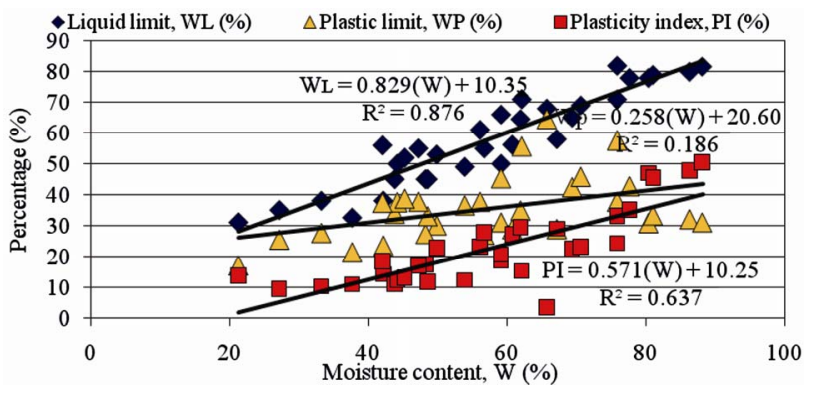

Figure 7. The empirical correlation between liquid limit, $\left(\mathrm{W}_{\mathrm{L}},\right)$, plastic limit, $\left(\mathrm{W}_{\mathrm{p}}\right)$, and plasticity index, (PI) with moisture content, $(W)$ of 32 clayey sand soil samples.

$\mathrm{R}^{2}$ was approximately 0.186 . Meanwhile, the empirical correlation between plasticity index, PI and moisture content, W of clayey sand soil samples is

$\mathrm{PI}=0.571 \mathrm{~W}+10.25$ and its regression coefficient, $\mathrm{R}^{2}$ was approximately 0.637 . It shows that the parameters are directly proportional to its resistivity values.

\section{Results and Discussion for Field Practices}

Beside than laboratory practices for soil samples from the study site, this study also using correlation in between modelling techniques for both geophysical methods which is 2 dimension electrical resistivity imaging, 2 dimension seismic refraction imaging and geotechnical engineering method of SLOPE/W for slope stability analysis during five months monitoring period. There are 5 in-field practices were carried out in period of five months of monitoring from January 2011 until May 2011. With adequate selection of field test, proper control over the procedures adopted and careful extraction of undisturbed samples, in situ tests can give better information about the behaviour of the residual clayey sand soils.

For January analysis, the subsurface condition can be shown as in Figure 8. The subsurface condition was consisted of clayey sand soil layer where the saturated zones have a low resistivity values in range of $5 \Omega \mathrm{m}$ to $300 \Omega \mathrm{m}$ at distance of 4.0 meter and 8.0 meter with depth of 2.0 meter and 3.0 meter respectively. Meanwhile, there are dried soil's zones which have high resistivity in range 

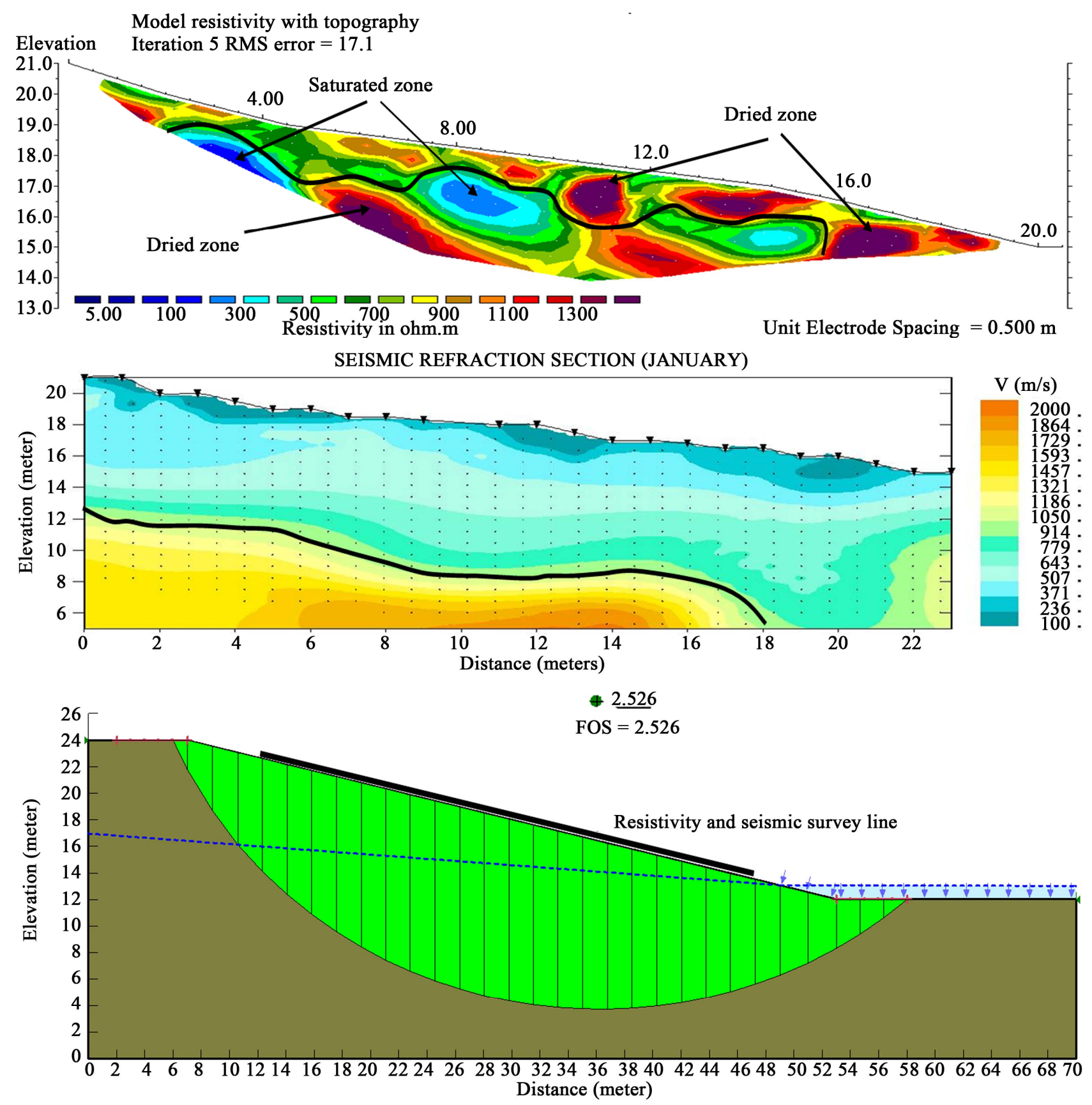

Figure 8. January subsurface structure analysis.

of $1300 \Omega \mathrm{m}$ to $2000 \Omega \mathrm{m}$ at distance of 6.0 meter, 11.0 meter and 18.0 meter with depth of 1.0 meter and 3.0 meter respectively. The present of these saturated zones and the dried zones could be associated with weak zone and compacted soil. From the 2-D seismic refraction result, the subsurface condition also consisted of weak zone and dried zones of soil. Figure 8 shows a 2-D seismic refraction result for January analysis. The subsurface consist of three main zones, first layer with velocity value of $370-500 \mathrm{~m} / \mathrm{s}$ which associated as loose soil mix with boulders. The second zone with velocity value of
$600-800 \mathrm{~m} / \mathrm{s}$ which associated with hard layer located at depth $2.0-5.0 \mathrm{~m}$. The third with velocity value larger than $1000 \mathrm{~m} / \mathrm{s}$ with associated as moist layer at depth 4.0 8.0 meter. By using SLOPE/W software and Morgenstern-Price analysis type, the Factor of Safety (FOS) of slope stability analysis is 2.526 .

For February analysis, the subsurface condition can be shown as in Figure 9. The subsurface condition was consisted of clayey sand soil layer where the saturated zones have a low resistivity values in range of $5 \Omega \mathrm{m}$ to $400 \Omega \mathrm{m}$ at distance of 4.0 meter and 8.0 meter with depth of 

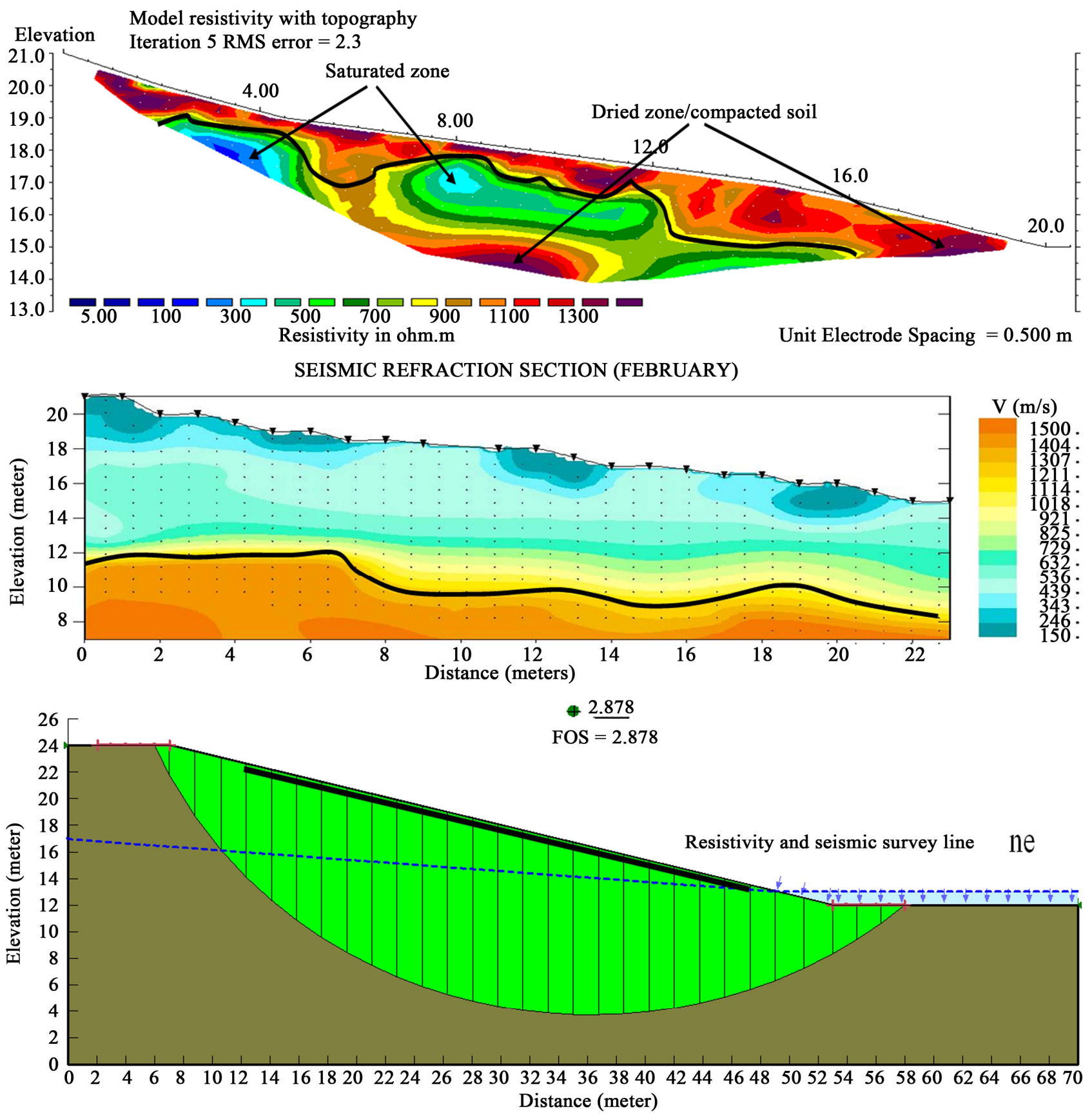

Figure 9. February subsurface structure analysis.

2.0 meter and 3.0 meter respectively. Meanwhile, there are dried zones or compacted soils which have high resistivity in range of $1300 \Omega \mathrm{m}$ to $2000 \Omega \mathrm{m}$ at distance of 10.0 meter and 18.0 meter with depth of 1.0 meter and 4.0 meter respectively. The present of these saturated zones and the dried zones could be associated with weak zone and compacted soils. From the 2 dimension seismic refraction result, the subsurface condition also consisted of loose contact soil and dried zones of soil. This seismic refraction result also supported by the 2 dimension electrical resistivity result. The subsurface consist of three main zones, $350-600 \mathrm{~m} / \mathrm{s}$ with associated as loose soil mixed with boulders. The second zone with velocity value of $700-900 \mathrm{~m} / \mathrm{s}$ with associated with hard layer at depth 2.0 - 5.0 meter. Meanwhile third zone with velocity value of greater $1100 \mathrm{~m} / \mathrm{s}$ considered as moist layer. By using SLOPE/W software and Morgenstern-Price analysis type, the Factor of Safety (FOS) of slope stability analysis is 2.878 .

For March analysis, the subsurface condition can be shown as in Figure 10. The subsurface condition was consisted of clayey sand soil layer where the saturated zones 

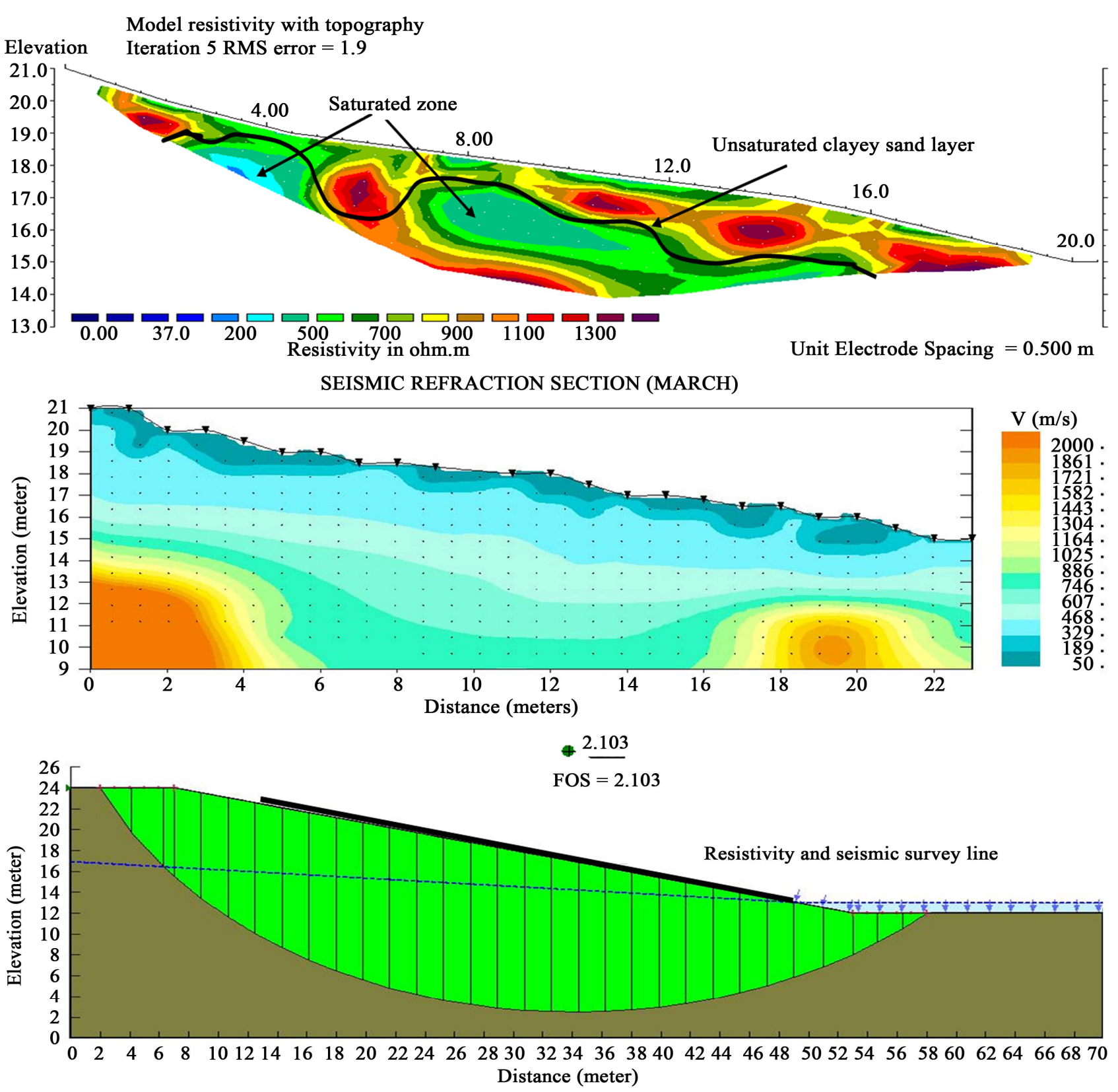

Figure 10. March subsurface structure analysis.

have a low resistivity values in range of $5 \Omega \mathrm{m}$ to $400 \Omega \mathrm{m}$ at distance of 4.0 meter and 8.0 meter with depth of 2.0 meter and 3.0 meter respectively. Meanwhile, there are moist zones or less compacted soils which have high resistivity in range of $1300 \Omega \mathrm{m}$ to $2000 \Omega \mathrm{m}$. The present of these saturated zones and the moist zones could be associated with weak zone and be able to reduce the stability of slope. From the 2 dimension seismic refracttion result, the subsurface condition also consisted of loose soil zones of clayey sand soil. 2-D seismic refraction result for March analysis as shows in Figure 10. The subsurface consist of three main zones. The first zone with velocity value of $400-600 \mathrm{~m} / \mathrm{s}$ which considered as loose soil mixed with boulders. The second zone with velocity value of $700-900 \mathrm{~m} / \mathrm{s}$ with associated as hard layer at depth 2.0 - 5.0 meter. The third zone with velocity value of grater than $1200 \mathrm{~m} / \mathrm{s}$ with associated as moist layer at depth 4.0 - 8.0 meter. By using SLOPE/W software and Morgenstern-Price analysis type, the Factor of Safety (FOS) of slope stability analysis is 2.103 which are lesser than January and February analysis.

For April resistivity analysis, the subsurface condition can be shown as in Figure 11. The subsurface condition was consisted of clayey sand soil layer where the saturated zones have a low resistivity values in range of 5 $\Omega \mathrm{m}$ to $300 \Omega \mathrm{m}$ at distance of 4.0 meter and 8.0 meter 

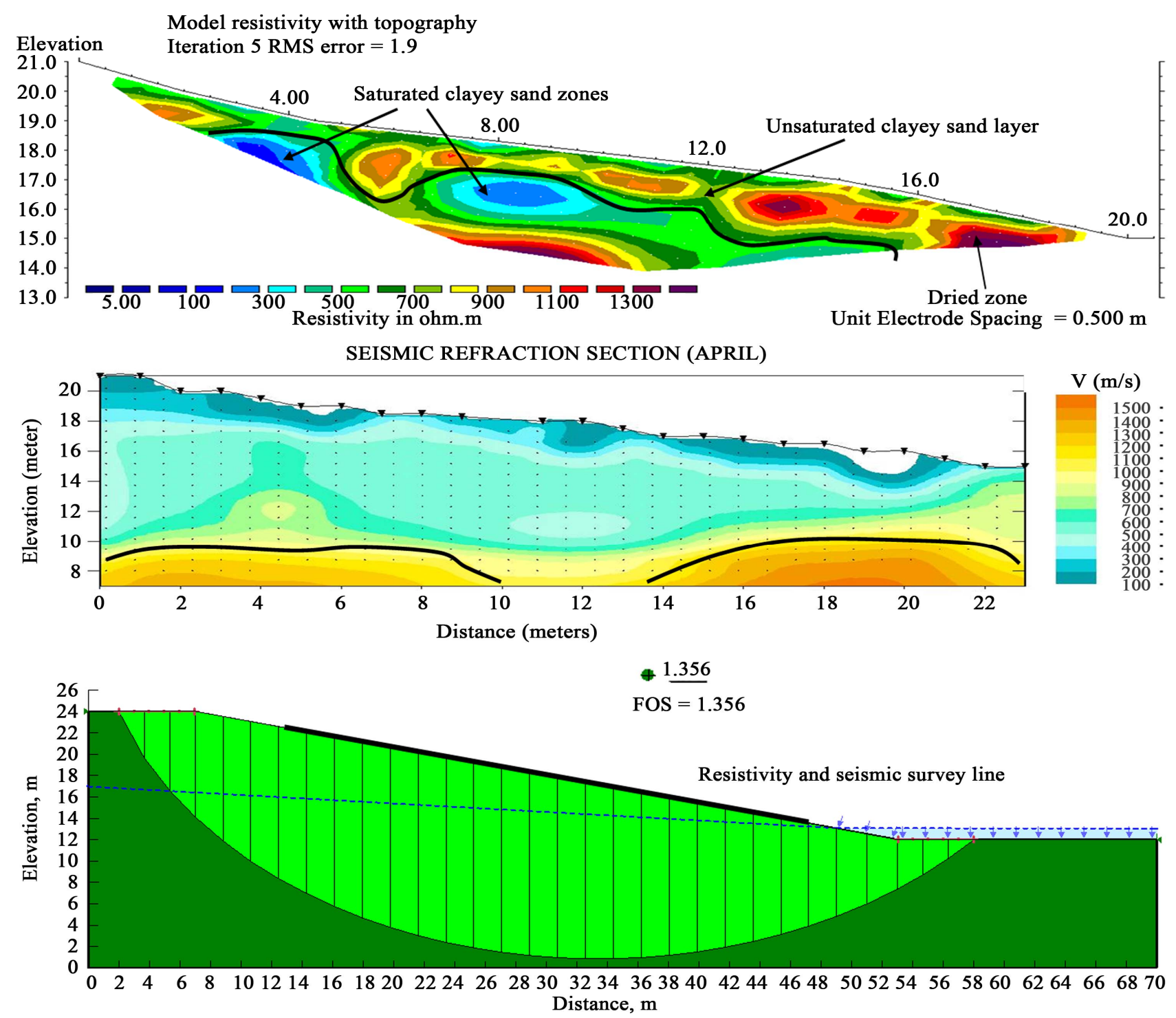

Figure 11. April subsurface structure analysis.

with depth of 2.0 meter and 3.0 meter respectively. The volume of this saturated clayey sand zones are larger than March analysis. Meanwhile, there are dried zones or compacted soils at distance 10.0 meter and 18.0 meter which have high resistivity in range of $1300 \Omega \mathrm{m}$ to 2000 $\Omega \mathrm{m}$ at a depth of 1.0 meter and 4.0 meter from the Earth surface respectively. The present of these saturated zones and the dried zones could be associated with weak zone and compacted clayey sand soils. From the 2 dimension seismic refraction result, the subsurface condition also consisted of unsaturated and saturated clayey sand soil layer. This seismic refraction result also supported by the 2 dimension electrical resistivity result. The subsurface consist of three main zones. The first zone which has velocity value of $400-600 \mathrm{~m} / \mathrm{s}$ which considered as loose soil mixed with boulders. Second layer with velocity value of $600-800 \mathrm{~m} / \mathrm{s}$ with associated as hard layer at de- pth 5.0 - 7.0 meter. The third zone has velocity value greater than $1100 \mathrm{~m} / \mathrm{s}$ which considered as moist layer at depth 8.0 - 9.0 meter. By using SLOPE/W software and Morgenstern-Price analysis type, the Factor of Safety (FOS) of slope stability analysis is 1.356 .

For May resistivity analysis, the subsurface condition can be shown as in Figure 12. The subsurface condition was consisted of clayey sand soil layer where the saturated zones have a low resistivity values in range of 5 $\Omega \mathrm{m}$ to $500 \Omega \mathrm{m}$ located at distance of 4.0 meter and 8.0 meter with depth of 2.0 meter and 3.0 meter respectively. Meanwhile, there are dried zones or compacted clayey sand soils which have high resistivity in range of 1300 $\Omega \mathrm{m}$ to $2000 \Omega \mathrm{m}$ located at distance of 10.0 meter and 18.0 meter with depth of 1.0 meter and 4.0 meter from the Earth surface respectively. The present of these saturated zones and the dried zones could be associated with 

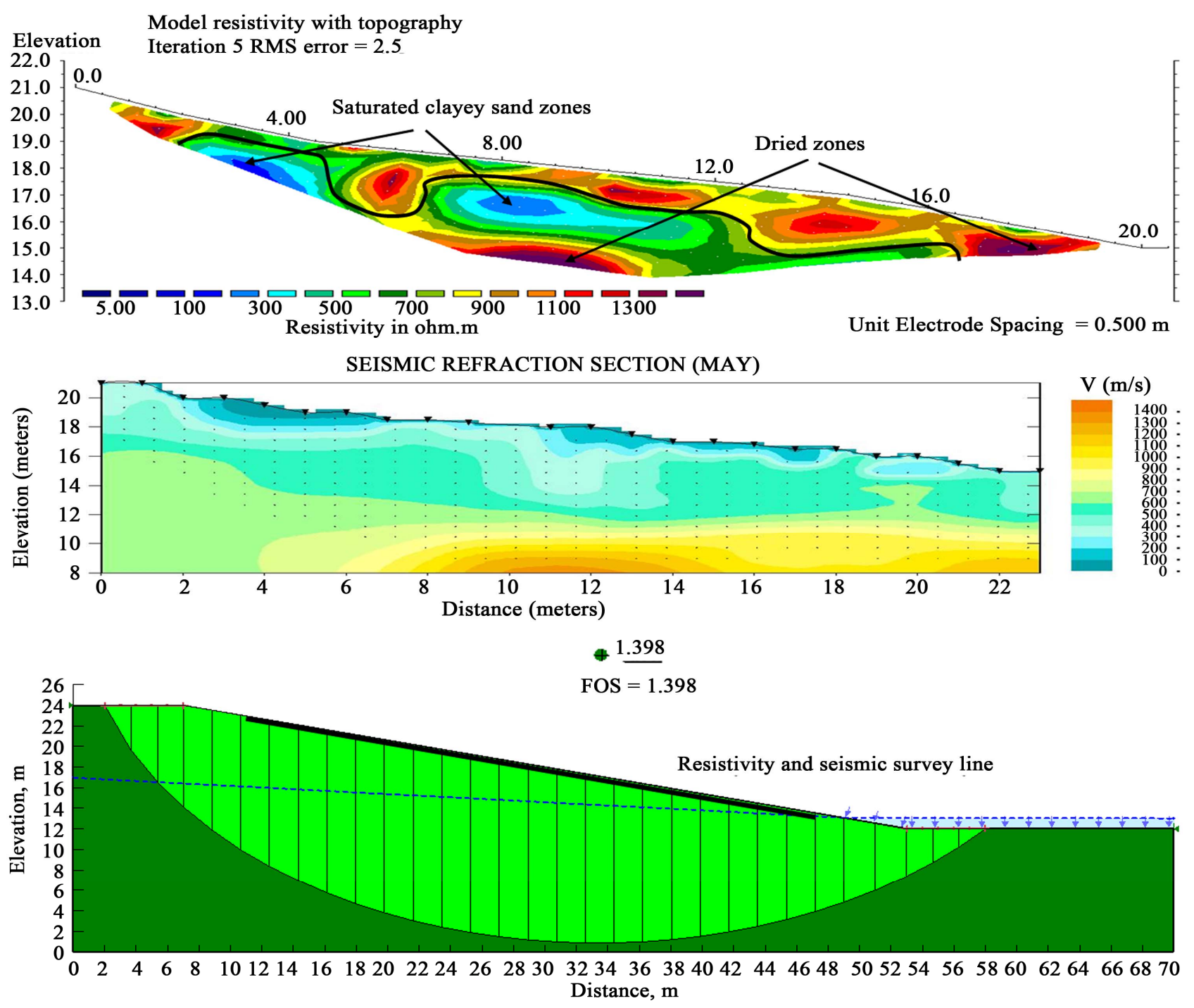

Figure 12. May subsurface structure analysis.

weak zone and compacted clayey sand soils. From the 2-D seismic refraction result, the subsurface condition also consisted of unsaturated and saturated clayey sand soil layer. This seismic refraction result also supported by the 2-D electrical resistivity result. The subsurface consist of three main zones. The first zone with velocity value of $400-600 \mathrm{~m} / \mathrm{s}$ which considered as loose soil mixed with boulders. The second zone with velocity value of $600-900 \mathrm{~m} / \mathrm{s}$ with associated as hard layer at depth 3.0 - 6.0 meter. Meanwhile, the third zone with velocity value of greater than $1000 \mathrm{~m} / \mathrm{s}$ with associated as moist layer at depth of $9.0-10.0$ meter. By using SLOPE/$W$ software and Morgenstern-Price analysis type, the Factor of Safety (FOS) of slope stability analysis is 1.398 .

Figure 13 shows the empirical correlation between field test of resistivity and seismic refraction. The relation for both field tests is $\mathrm{V}_{\mathrm{p}}=-0.196(\rho)+569.6$. It shows that seismic velocity is inversely proportional to

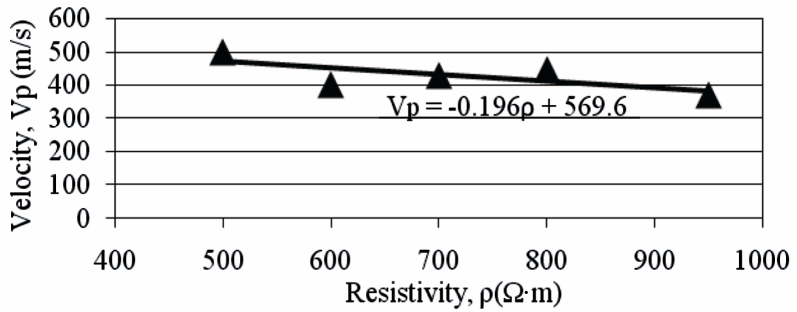

Figure 13. Empirical corelation between field tests of resistivity and seismic refraction

resistivity values.

This relation shows that, water content plays important role by influence the resistivity and seismic values. The resistivity value is lower when more water is present and higher when less or no water present in soils. Meanwhile, seismic value is higher when water is mixed with soil and lower when less or no water present in soil. 


\section{Conclusions and Recommendation}

Soil behaviour of clayey sand soils study is difficult and challenging study especially for monitoring and investigative techniques. In this research, two technical techniques were used in purpose of monitoring and investigate the physical characterizations of study area. The integrated study of the physical environment with monitoring and investigative techniques by using electrical resistivity and seismic refraction surveys with engineering laboratory practices for soil samples collected from the investigated area is succeed in reaching the objectives of this research.

Generally, after analyzing the data obtained collectively from 32 samples of clayey sand soil within five months monitoring period located on Batu Uban area of Penang Island, the following conclusions and recommendations are made.

- The moisture content can influence the soil's strength and resistivity values. The present of moisture content can reduce the soil's strength $\left(\varnothing^{\prime}\right)$ by lose its soil particles chain and it also able to increase the soil's conductivity.

- Shear strength of this soil is determined by the angularity of the sand particles and moisture content.

- The moisture content significantly modifies their strength $\left(\varnothing^{\prime}\right)$. As moisture increase - strength decreases. This is because increasing moisture content cause greater separation of soil particles and further, causes softening of soil cements.

- The empirical correlations models in this study are successfully determine to show strong correlations with granitic residual soils of Batu Uban area which significant to tropical clayey sand soil's behaviour.

The electrical resistivity and seismic refraction surveys which were used in this study on the test site, delivered a detailed image of the near-surface conditions. Electrical resistivity and seismic refraction resolution analysis proved that a combination of these integrated study of the physical environment data provided a reasonable compromise between measurement time and image resolution.

\section{REFERENCES}

[1] R. J. Small and M. J. Clark, "Slope and Weathering," Cambridge University Press, Cambridge, 1982.

[2] R. Z. Abidin and B. Sujak, "Relationship between Rainfall and Landslide Events in Malaysia," International Conference on Geotechnical and Highway Engineering (Geotropika), Kuala Lampur, 26-27 May 2008.

[3] A. A. Bery, R. Saad, N. M. Mustaza, N. A. Ismail, N. El Hidayah Ismail and E. Tonnizam, "Slope Stability Analysis via Soil's Geotechnical Properties and Its Geophysical Characterizations," National Geoscience Conference, Malaysia, 11-12 June 2011.

[4] B. Heincke, T. Gunther, E. Dalsegg, J. S. Ronning, G. V.
Ganerod and H. Elvebakk, "Combined Three Dimensional Electrical and Seismic Tomography Studies on the Anknes Rockslide in Western Norway," Journal of Applied Geophysics, in press.

[5] D. Jongmans, G. Bievre, F. Renalier, S. Schwartz, N. Beauresz and Y. Orengo, "Geophysical Investigation of a Large Landslide in Glaciolacustrine Clays in the Trieves Area (French Alps)," Engineering Geology, Vol. 109, No. 1-2, 2009, pp. 45-56. doi:10.1016/j.enggeo.2008.10.005

[6] S. Thevanayagam and G. R. Martin, "Liquefaction in Silty Soils-Screening and Remediation Issues," Soil Dynamics and Earthquake Engineering, Vol. 22, No. 9-12, 2002, pp. 1035-1042. doi:10.1016/S0267-7261(02)00128-8

[7] V. C. Xenaki and G. A. Athanasopoulos, "Liquefaction Resistance of Sand-Silt Mixtures: An Experimental Investigation of the Effect of Fines," Soil Dynamics and Earthquake Engineering, Vol. 23, No. 3, 2003, pp. 183194. doi:10.1016/S0267-7261(02)00210-5

[8] S. A. Naeini and M. H. Baziar, "Effect of Fines Content on Steady-State Strength of Mixed and Layered Samples of Sand," Soil Dynamics and Earthquake Engineering, Vol. 24, No. 3, 2004, pp. 181-187. doi:10.1016/j.soildyn.2003.11.003

[9] P. V. Lade, C. D. Liggio Jr. and J. A. Yamamuro, "Effects of Non-Plastic Fines on Minimum and Maximum Void Ratios of Sand," Geotechnical Testing Journal, Vol. 21, No. 4, 1998, pp. 336-347. doi:10.1520/GTJ11373J

[10] B. O. Hardin, "1-D Strain in Normally Consolidated Cohesionless Soils," Journal of Geotechnical Engineering Division, Vol. 113, No. 12, 1987, pp. 1449-1467. doi:10.1061/(ASCE)0733-9410(1987)113:12(1449)

[11] J. M. Pestana and A. J. Whittle, "Compression Model for Cohesionless Soils," Geotechnique, Vol. 45, No. 4, 1995, pp. 611-631. doi:10.1680/geot.1995.45.4.611

[12] J. A. Yamamuro, P. A. Bopp and P. V. Lade, "One Dimensional Compression of Sands at High Pressures," Journal of Geotechnical Engineering, Vol. 122, No. 2, 1996, pp. 147-154.

doi:10.1061/(ASCE)0733-9410(1996)122:2(147)

[13] F. A. Chuhan, A. Kjeldstad, K. Bjorlykke and K. Hoeg, "Experimental Compression of Loose Sands: Relevance to Porosity Reduction during Burial in Sedimentary Basins," Canadian Geotechnical Journal, Vol. 40, No. 5, 2003, pp. 995-1011. doi:10.1139/t03-050

[14] F. David, "Essentials of Soil Mechanics and Foundations Basic Geotechnics," 6th Edition, Pearson Education, Upper Saddle River, 2007.

[15] A. Shakoor and E. H. Barefild, "Relationship between Unconfined Compressive Strength and Degree of Saturation for Selected Sandstones," Environmental and Engineering Geoscience, Vol. 15, No. 1, 2009, pp. 29-40. doi:10.2113/gseegeosci.15.1.29

[16] B. Vásárhelyi and P. Ván, "Influence of Water Content on the Strength of Rock," Engineering Geology, Vol. 84, No. 1-2, 2006, pp. 70-74. doi:10.1016/j.enggeo.2005.11.011

[17] M. Romana and B. Vásárhelyi, "A Discussion on the Decrease of Unconfined Compressive Strength between 
Saturated and Dry Rock Samples," Polytechnic University of Valencia, Spain, 2007.

[18] E. Barefield and A. Shakoor, "The Effect of Degree of Saturation on the Unconfined Compressive Strength of Selected Sandstones," International Association for Engineering Geology and the Environment, The Geological Society of London, 2006.

[19] A. Namdar, "Mineralogy in Geotechnical Engineering. Mysore University, India," Journal of Engineering Science and Technology Review, Vol. 3, No. 1, 2010, pp. 108-110.

[20] T. C. Kenney, "Residual Strength of Mineral Mixtures," Proceedings 9th International Conference on Soil Mechanics and Foundation Engineering, Vol. 1, 1977, pp. 155-160.

[21] J. K. Lupini, A. E. Skinner and P. R. Vaughan, "The Drained Residual Strength of Cohesive Soils," Geotechnique, Vol. 31, No. 2, 1981, pp. 181-213. doi:10.1680/geot.1981.31.2.181
[22] J. H. Yin, "Properties and Behaviour of Hong Kong Marine Deposits with Different Clay Contents," Canadian Geotechnical Journal, Vol. 36, No. 6, 1999, pp. 10851095.

[23] H. Rahardjo, E. C. Leong and S. K. Tang, "Characterisation and Engineering Properties of Singapore Residual Soils," Proceeding of Specialty Workshop on Characterisation and Engineering Properties of Natural Soils, National University of Singapore, Singapore, 2003, pp. 1279-1304.

[24] E. Tonnizam, I. Komoo, K. A. Kassim and N. Gofar, "Influence of Moisture Content on the Strength of Weathering Sandstone," Malaysian Journal of Civil Engineering, Vol. 20, No. 1, 2008, pp. 137-144.

[25] N. Fabiola, B. Giarola, A. P. da Silva, S. Imhoff and A. R. Dexter, "Contribution of Natural Soil Compaction on Hardsetting Behaviour," Geoderma, Vol. 113, No. 1-2, 2003, pp. 95-108. doi:10.1016/S0016-7061(02)00333-6 